\title{
PERSPECTIVA, METÁFORA Y HERMENÉUTICA
}

\author{
JOSÉ L. SERRANO RIBEIRO \\ U.N.E.D. (España)
}

\begin{abstract}
RESUMEN: Un modo productivo de enfocar el problema derivado de las relaciones entre el sujeto, el lenguaje y la realidad, es contando con una teoría perspectivista, como la de Ortega, de gran solidez ontológica, fenomenológica y hermenéutica. El entorno humano está acondicionado por deseos, perspectivas y palabras, que exigen al sujeto sostener un nuevo vínculo con la realidad, con los otros y consigo mismo. En este contexto se impone el proceso metafórico como la forma más auténtica de ser, interpretar y decir. Pero no hay que olvidar la otra cara de la metáfora, pues aunque es un eficaz dispositivo de interpretación, también posee el poder de ocultar, dependiendo de la perspectiva usada. El sujeto aparece, así, como la obra inacabada del proceso metafórico, de las interpretaciones y de los símbolos que, al manejarlos, le manejan, formando con el lenguaje y la realidad un sistema integrado.
\end{abstract}

PALABRAS CLAVE: deseo, hermenéutica, lenguaje, metáfora, perspectiva, realidad, sujeto.

\section{Perspective, Metaphor and Hermeneutics}

ABSTRACT: A productive way of approaching the problem arising from the relations between subject, language and reality, is relying on a perspectivist theory, like the one by ORTEGA, of a great ontological, phenomenological and hermeneutic solidity. The human environment is conditioned by desires, perspectives and words, requiring the subject to maintain new links with reality, the others and himself. In this context the metaphoric process is imposed as the most authentic way of being, interpreting and speaking. But we must not forget the other side of the metaphor, because while it is an effective device for interpretation, it also possesses the power to hide, depending on the perspective used. Thus, the subject appears as an unfinished work of metaphoric process, the interpretations and the symbols, which, while being handled, handle the very subject, producing an integrated system with language and reality.

KEY WORDS: desire, hermeneutics, language, metaphor, perspective, reality, subject.

\section{Prejuicio y PeRsPectiva}

Cuando el torero Jesulín de Ubrique era popular, sus imitadores le parodiaban repitiendo: "eso es como un toro...» El personaje, presa de la estrechez de perspectiva bajo la cual veía el mundo, interpretaba cualquier cosa en términos del toro: «tomaba 'algo' por un toro». Esta imagen de la eterna metáfora nos puede servir para añadir una cláusula a la fórmula hermenéutica de GADAMER (cfr. 2000, p. 32): «interpretar es tomar algo por algo», y a la de RicoeuR (cfr. 1999, p. 75): «interpretar es hacer familiar lo extraño». Ahora, con el suplemento, las fórmulas presentarían este aspecto: interpretar y metaforizar es 'tomar algo por algo' o 'hacer familiar lo extraño' según un punto de vista dado. Y tengamos en cuenta que la perspectiva usada puede ser tan cotidiana que proceda de algún prejuicio.

Si creíamos que lo mejor era deshacerse de los prejuicios porque enturbian la visión de la realidad, para Gadamer y Ortega constituyen una influencia decisiva e inevitable, por lo que habrá que contar con ellos en las interpretaciones al formar parte de éstas: si prejuicio no significa falso juicio sino situación hermenéutica, habrá que rehabilitar el concepto y aceptar que existen prejuicios legítimos (cfr. GADAMER, 1995, p. 337); en ORTEGA, (cfr. 1983, pp. 473-474) piensa que quien considera algo sin prejuicios actúa 
como los animales, que parecen mirar las cosas siempre por vez primera. Los prejuicios son necesarios para juzgar e imprescindibles en la continuidad de la cultura. Según esta caracterización positiva, los prejuicios mediatizan la percepción de la realidad, constituyen una condición más del comprender, actúan buscando perspectivas, e incurrimos en el peor de los prejuicios si creemos que nos hemos librado de ellos. Una crítica rigurosa de los prejuicios nos llevaría a una situación de perplejidad, pues ¿desde qué lugar exento de prejuicios deberíamos llevarla a cabo?

Las perspectivas procedentes de prejuicios nos conducen a interpretaciones y metáforas (tomando algo por algo en cuanto a algo), sean o no aceptadas por la comunidad intelectual. El Sol seguirá saliendo aunque sea la Tierra la que se mueve y el frío entrará por la ventana aunque sea el calor el que se escapa. Esta variedad angular que presenta la realidad, nos servirá de hilo conductor para comentar la teoría orteguiana del perspectivismo, dada su relevancia hermenéutica a la hora de entender las relaciones que se decantan entre sujeto, lenguaje y realidad, y sus respectivos horizontes cuando se funden en la aplicación metafórica, tanto para interpretar como para encubrir, dependiendo de la perspectiva empleada.

\section{El PERSPECTIVISMO COMO ESPEJISMO}

Antes de examinar el perspectivismo orteguiano veamos algunos antecedentes. LEIBNIZ dice en su Monadología (§ 57) que si al contemplar una ciudad desde diversos ángulos parece que son ciudades diferentes, en el universo ocurre lo mismo; y aunque justifica las múltiples perspectivas en función de las infinitas sustancias simples, olvida la importancia de la realidad objetiva: «la perspectiva no viene (...) en Leibniz de la condición de la realidad, sino de la irreductible pluralidad de las mónadas» (MARías, 1973, p. 179), aparte de que concede la existencia de un punto de vista correcto en detrimento de los demás, como en esos dibujos que son caóticos hasta que no se los observa desde una privilegiada posición. Quizá tal perspectivismo haya influido en Ortega pero, en éste, la perspectiva depende tanto del observador como de la realidad, por lo que no existe un punto de vista mejor que otro.

Un perspectivismo más afín al de Ortega es el de Chladenius (siglo XvIII), autor de la hermenéutica universalista y pedagógica que figura en su Introducción a la interpretación correcta de las oraciones y textos científicos. También reconoce a Leibniz como el fundador del perspectivismo, pues acuñó la expresión «punto de vista» con una intención filosófica, y retoma el concepto para integrarlo en su hermenéutica. Sehepunkt (punto de mira) es la traducción del término latino scopus, crucial en las hermenéuticas de Agustín, Flacius y Melanchton. Al interpretar siempre lo hacemos desde un punto de mira, desde una finalidad o intención. El scopus de una lista de la compra, por ejemplo, no es el mismo que el de un inventario, aunque los artículos sean idénticos. El punto de mira se define, de forma preliminar, como la situación, el estado y la disposición general del intérprete.

Más de cien años después, aparece el perspectivismo de Nietzsche (2001, pp. $307-$ 308): "Éste es (...) el perspectivismo como yo lo entiendo. La naturaleza de la conciencia animal implica que el mundo de que podemos llegar a ser conscientes es meramente un mundo de superficies». El mundo filtrado por la conciencia humana es considerado desde la perspectiva de lo superficial, por eso tal conciencia retiene tan sólo una imagen parcial de éste sin penetrar su piel. Si en el perspectivismo leibniziano la conciencia de cada sujeto corresponde a una mónada distinta, en el de Nietzsche la conciencia es 
entendida en sentido gregario. El ser humano se sitúa en un punto de vista interesado para su propia conservación, y desde ahí capta, entiende e interpreta cualquier fenómeno, tanto natural como moral: sólo comprendemos el mundo que nosotros mismos construimos. Los valores surgen a partir de un punto de vista pragmático que pretende la superación del hombre, la protección de la vida y su continuidad (cfr. NiETZsche, 1981, pp. 166 y 283). Este perspectivismo aparece asociado al tema de la verdad, del conocimiento y del engaño, a la idea de que el mundo sólo es un constructo hermenéutico del hombre: si éste ha elaborado interpretativamente su mundo de hechos y valores, por más respeto que sintamos por la verdad, habrá que admitir que se trata de una verdad inventada a partir de ilusiones y conveniencias. Como Nietzsche concibe el conocimiento desde la utilidad vital, su teoría del punto de vista desemboca en la eliminación de la diferencia entre verdad y mentira: "La verdad es el error sin el que no puede vivir ningún ser viviente» (NIETZSCHE, 1981, p. 282); además, "las verdades son ilusiones de las que se ha olvidado que lo son" (Nietzsche, 1998, p. 25). Si el perspectivismo de Leibniz concluía que, de entre todos los puntos de vista sólo hay uno verdadero, el de Nietzsche afirma que por existir una infinidad de perspectivas ninguna es la verdadera: «Leibniz nos habia enseñado que no hay puntos de vista sobre las cosas, sino que las cosas, los seres, eran puntos de vista. (...) Con Nietzsche (...) el punto de vista se abre a una divergencia que afirma: es otra ciudad la que corresponde a cada punto de vista» (Deleuze, 2011, p. 209). Si tantos ojos ven cosas tan distintas, ¿cómo elegir la mirada correcta?

El perspectivismo de Nietzsche fue rehabilitado por Vaihinger, quien cita multitud de sus aforismos equiparando ficción y perspectiva: "A estas ficciones (...) las llama Nietzsche perspectivas» (VAIHINGER 1998, p. 74). ¿Qué son estas perspectivas o falacias que nada tienen que ver con la realidad pero de las que el hombre no puede prescindir?: son conceptos creados para organizar el mundo y abrirse camino. Objeto y sujeto, activo y pasivo, causa y efecto, medio y fin, fenómeno y cosa-en-sí, sustancia y conciencia, naturaleza y cultura sólo son «meras formas de perspectiva. Tales 'falsificaciones perspectivas' (...) son necesarias para la existencia del hombre» (VAIHINGER, 1998, p. 75). Pero tanto este perspectivismo como el de Nietzsche no casan con el de ORTEGA (1966a, p. 23): «nada tiene de común esta doctrina con lo que bajo el mismo nombre piensa Nietzsche en su obra póstuma 'La Voluntad de Poderío', ni con lo que, siguiéndole, ha sustentado Vaihinger en su libro reciente 'La filosofía del Como si'». Perspectiva es lo contrario de realidad, y significa ilusión, apariencia y convención necesaria para la vida, mientras que en Ortega la perspectiva, aparte de ser condición indispensable de la realidad, es la vía de acceso a la verdad. La falsedad reside en obviar las perspectivas o considerar como verdadera sólo una de ellas. Lo que quiere ORTEGA es «eliminar la ficción; (...) lo contrario de Nietzsche y Vaihinger» (MARÍAs, 1973, p. 177).

Un perspectivismo que no conviene olvidar es el de G. Teichmüller (siglo XIX), quien analizó el carácter perspectivista de los supuestos metafísicos clásicos que agrupó en tres bloques: "positivismo-materialismo-empirismo», «idealismo-platonismo», y "spinozismo-monismo", todos de tendencia objetivista. Estos tres sistemas genéricos son representaciones proyectivas del contenido del conocimiento, y al estar forzosamente referidos a un punto ocular (Augenpunkt) del sujeto cognoscente, sólo suponen concepciones virtuales del mundo. Éste, tal y como se da a la sensibilidad, está organizado en perspectivas, pero la realidad sólo está determinada por el pensamiento y no por la sensibilidad. "La perspectiva aparece siempre en Teichmüller (...) como apariencia frente a la realidad» (MARías, 1973, pp. 170-171). Por el contrario, en Husserl la perspectiva aparece como una característica esencial de la conciencia, es decir, la «intención» o su constante remitir a algo, pues distintas «intenciones» (perspectivas) implican distintos modos de captar la realidad objetiva. 


\section{El RENDIMIENTO HERMENÉUtico DEL PERSPECTIVISMO NO ILUSIVO}

Para Ortega, cada mente, cada vida, capta un fragmento de realidad, una región objetiva de ésta. El carácter objetivo de la realidad es muy importante para él, porque lo subjetivo nada tiene que ver con la perspectiva individual, sino con una forma de visión y entendimiento que deforma la realidad: «si hubiera entre los infinitos puntos de vista uno excepcional al que cupiese atribuir una congruencia superior con las cosas, cabría considerar los demás como deformadores»(ORTEGA, 1987a, p. 190). La subjetividad sólo implica el modo que tiene cada sujeto, en función de su talante y carácter, de reaccionar ante las influencias del medio: "como (...) es siempre la cosa quien se manifiesta a un punto de vista en alguno de sus aspectos, éstos le pertenecen y no son «subjetivos»»(ORTEGA, 1998b, p. 36). La diferencia observada en un objeto al cambiar de perspectiva, sería la misma para todo observador en esa misma posición. La teoría orteguiana del punto de vista no se basa en la subjetividad, aunque ésta se encuentre influenciada por la estructura dinámica de la realidad; pero el perspectivismo se impone tan pronto como sujeto y objeto cesan de funcionar en sentido utópico y reclaman su efectividad ontológica: «la perspectiva es uno de los componentes de la realidad. Lejos de ser su deformación, es su organización. Una realidad que vista desde cualquier punto resultase siempre idéntica es un concepto absurdo» (ORTEGA, 1987b, p. 147).

Todas las perspectivas se conjugan para integrar la estructura de la realidad, y como no hay un punto de vista mejor que otro, ninguno puede ser excluido ni reemplazado: "Si se quiere dar cabal cuenta de la realidad, hay que darla desde la perspectiva en que cada uno está (...). La tesis de la complementariedad de las perspectivas es la que permite dar una solución airosa al problema de la multiplicidad de éstas» (Снаміzо, 1990, pp. 93-94). Podemos considerar el perspectivismo orteguiano como una aplicación geométrica y óptica vinculada a una concepción ontológica y epistemológica de lo real, por lo que sugiere además una apertura antropológica y psicológica. Un punto de vista siempre implica otro con el cual se relaciona. Sujeto y objeto están originariamente mediados, pues un desplazamiento epistemológico en el punto de vista del sujeto se corresponde con un desplazamiento ontológico en el objeto. No es casual que Ortega conceda tanta importancia a la mirada, pues se consideraba seguidor de los filósofos amigos del mirar: «mirando se hacen las dos terceras partes de toda filosofía que no sea una escolástica» (MARÍAS, 1971, p. 105); es más, mirada, perspectiva y fenomenología constituyen una terna de relevancia filosófica.

La recursión epistemológica en la que podría derivar este perspectivismo es advertida de modo crítico por Grondin, (1999, p. 37): “¿cómo podemos estar tan seguros de que todo sea tan extremadamente perspectivista? ¿Acaso el perspectivismo no es también sólo una perspectiva entre otras?» A la primera pregunta contestamos con otra invirtiendo la cuestión: ¿cómo estar seguros de que todo no es perspectivista?; además, no se trata de estar seguros por haber verificado tal extremo con una referencia exenta de perspectiva, sino que la propia experiencia así lo muestra: «No existe (...) esa supuesta realidad inmutable y única con quien comparar los contenidos (...): hay tantas realidades como puntos de vista. El punto de vista crea el panorama» (ORTEGA, 1983, p. 475). Todo es tan perspectivista porque disponemos de un panorama. Y en la segunda pregunta, el defecto lógico que advierte Grondin se basa en el argumento que a veces se ha lanzado contra el relativismo, no respetando su espíritu y fijándose sólo en la letra; pero el perspectivismo de Ortega no es subjetivismo ni relativismo (ni tampoco dogmatismo o escepticismo). $\mathrm{Si}$, como cree Grondin, el perspectivismo sólo es una perspectiva más entre otras, estas otras no podrían ser también perspectivismos; pero, aún así, llamemos a estos «-ismos» 
posibles como sea, quedará implícito en su última pregunta que no por ello dejarán de implicar perspectivas: al final, su duda se vuelve contra él.

Al observar, por ejemplo, una mesa, una pared o cualquier cosa desde diferentes ángulos, nos haremos una idea del objeto, aunque incompleta. Al interesarnos por una hoja, pongamos por caso, comprobaremos que no todos sus detalles se revelan al instante sino que irán apareciendo poco a poco, aportándonos la escena multitud de datos: manchas, tonos, pliegues, cuarteados, estomas y nervios, tanto porque nuestro ojo se desplaza de una región a otra de la hoja, como porque ésta solicita nuestra atención sobre diferentes áreas; y la clave de tal experiencia es que «yo no he acabado nunca de ver una hoja» (ORTEGA, 1998b, p. 34). Y no por cambiar de ángulo nos haremos totalmente con la cosa: aunque recorramos toda la superficie de una naranja, pongamos ahora por caso, sólo tendremos una sarta de perspectivas, el desarrollo del paralaje, un panorama: "primero vemos de ella sólo una cara, un hemisferio (...) y luego tenemos que movernos $e$ ir viendo hemisferios sucesivos. A cada paso, el aspecto de la naranja es otro (...), de suerte que nunca vemos junta la naranja y tenemos que contentarnos con vistas sucesivas»(ORTEGA, 1998b, p. 34). Esta problemática ya fue estudiada por Husserl como «la graduación del objeto de percepción», pues éste sólo se muestra escalonadamente: «este vaso, por ejemplo, lo puedo ver únicamente desde donde me encuentro y usted sólo desde donde se encuentra usted. Puedo girarlo, pero entonces lo veo de nuevo únicamente desde mi lado, y no veo la parte posterior, y a usted le pasa exactamente lo mismo" (GADAMER, 1998, p. 46). Anversos y reversos ensartados en el travelling no son la cosa entera, sino segmentos y secuencias de ésta. Cada plano es el semblante parcial y eventual que nos muestra objetivamente la realidad, pero no habría aspectos si nadie los viera, porque «el 'aspecto' de la cosa es inseparable del vidente»(ORTEGA, 1998b, p. 36).

La pedagogía del perspectivismo se revela generosa desde la visión, pero en ORTEGA (cfr. 1987b, p. 147) cubre un dominio más amplio. No sólo disponen de perspectivas el sujeto vidente y la realidad vista: cerremos los ojos y manipulemos un libro. También ahora se desplegarán un sinfín de perspectivas táctiles que tampoco agotarán los modos posibles de palparlo. Aquí también disponemos de una secuencia de aspectos bajo la cual examinamos su fisonomía: estas perspectivas sensibles apuntarán a representaciones noéticas, porque "ver y tocar las cosas no son, al cabo, sino maneras de pensarlas» (ORTEGA, 1983, p. 457). Y al hilo de esta idea, añade su discípulo: «la percepción queda referida al 'pensar' en un sentido lato, que incluye todo género de interpretaciones" ( $\mathrm{M}_{\mathrm{A}-}$ RÍAS, 1973, p. 173). Abramos los ojos, el libro y leámoslo. Aquí también comienza un nuevo campo de experiencias, ahora lingüísticas: seguir la trama de un relato, entender una descripción o un concepto. ¿Admitirá también el texto aspectos y perspectivas? Por supuesto que sí. Aunque al final de la lectura alcancemos una idea general, sólo será una entre varias, además, obtenida y orientada en sucesivos planos encadenados. Por muchos golpes de intuición hermenéutica que disfrutemos durante la lectura, nunca se cerrará la posibilidad activa y retroactiva de la aparición de otros.

Armar la interpretación y el conocimiento del objeto, ya sea una naranja o un texto pasa, para Ortega, por «la serie dialéctica» o la sucesión de momentos en los que se desarrollan las pesquisas para montar los aspectos retenidos: a) detenernos ante un aspecto; b) pasar al siguiente y a los demás; c) conservarlos en la memoria; y d) integrarlos en un panorama de comprensión (cfr. ORTEga, 1998b, pp. 41-42). Pero siempre estarán en juego aspectos y facetas, por no hablar de la perspectiva intelectual en la que nos situamos para leer, por ejemplo, el cuento de Caperucita en clave folklórica, ética, política o psicoanalítica: «es posible observar en cualquier objeto distintas facetas pulimentadas que muestran el objeto desde distintos ángulos, en varias 'refracciones' y 'fraccionamientos' 
que no son (...) simple 'apariencia'. Yo intento reproducir lingüísticamente por lo menos fragmentos del análisis espectral de las cosas, mostrándolas de forma simultánea de varios aspectos y entrelazadas con otras cosas: con cosas vecinas, consecutivas, contrapuestas. $Y$ ello porque soy desgraciadamente incapaz de mostrar las cosas en su totalidad» (GADAMER, 1998, p. 99).

La serie dialéctica nos ofrece interpretaciones, conocimientos e «ideas verdaderas» sobre la cosa, como cuando decimos que la naranja es grande o que el lobo engañó a Caperucita. La ecuación integral de todos sus aspectos es la cosa entera, y esta plenitud implica que posee más perfiles de los que prima facie hallamos. Al decir que la naranja es redonda y blanda, o que el lobo tenía hambre, expresamos ideas verdaderas que representan factores objetivos de esas realidades, aunque no las agoten descriptivamente. ¿De cuántas maneras puede decirse el ser? Si hubiera una sola, el perspectivismo no tendría sentido hermenéutico. Decir que la naranja es redonda no se contradice con añadir que es blanda y pesada, es más, esto suma una nota descriptiva: «la verdad, lo real, el universo, la vida (...) se quiebra en facetas innumerables»(ORTEGA, 1966a, p. 23). En efecto, la realidad es poliédrica.

No sólo hay que justificar este perspectivismo en virtud de las posiciones que puede ocupar un sujeto, sino también en base a la condición misma de la realidad que se brinda a sus miradas, pues "donde está mi pupila no está otra: lo que de la realidad ve mi pupila no lo ve otra. Somos insustituibles, somos necesarios» (ORTEGA, 1966a, p. 24). El mundo no se capta en un solo golpe de percepción porque es susceptible de innumerables perspectivas. La experiencia (Erlebnis) está sometida a la perspectiva, al proceso de ensamblaje de múltiples y diferentes planos; "la realidad, precisamente por serlo y hallarse fuera de nuestras mentes individuales, sólo puede llegar a éstas multiplicándose en mil caras o haces»(ORTEGA, 1966a, p. 23). Por ejemplo, ¿quién puede ver la Luna? Se nos dirá que quien disponga de un buen telescopio. Pero aun así, no vería el satélite al completo, sino la parte visible, la superficie proyectada sobre la lente en dos dimensiones, pero nunca la cara oculta ni por supuesto sus interioridades. Y da igual qué objeto sea: «si por ver se entiende (...) una función meramente sensitiva, (...) nadie ha visto jamás una naranja» (ORTEGA, 1998a, p. 105).

La experiencia nos remite a una reunión incompleta, tanto espacial como temporal, de algunas de las vistas que descubrimos en cada objeto: ciudades, hojas o bosques, pero también historias, fenómenos o situaciones. Cada objeto se integra en nuestro ámbito de comprensión gracias al punto de vista bajo el cual se nos muestra, pues «en la comprensión siempre nos encontramos ya en una situación determinada y (...), por tanto, representa una posición que limita las posibilidades de ver» (SANTIAGO, 1997, pp. 29-30). Contamos con dos posiciones: la del objeto y la nuestra, dos horizontes que en el proceso de comprensión se funden. Podemos advertir cómo el perspectivismo de Ortega tiene gran afinidad hermenéutica con la noción de horizonte en GADAMER: «la posibilidad de poder ver queda supeditada a un punto de vista, ya que no nos es dado un punto absoluto desde el que pudiéramos contemplar todo. Y ese ámbito de la visión que encierra todo lo que es visible desde ese punto de vista determinado es lo que Gadamer llama horizonte» (SAntiago, 1997, p. 30).

Pero los intereses del filósofo alemán giran más en torno al rendimiento hermenéutico del lenguaje, de los textos en general (religiosos, jurídicos, filosóficos, históricos, literarios, científicos), del diálogo, la traducción y el otro, del arte y la poesía, del ámbito social o de los efectos de la historia, que al del análisis interpretativo de los objetos utilizados en los típicos ejemplos orteguianos. Si en Ortega la serie dialéctica enhebraba las perspectivas en un panorama, en Gadamer se trata de fundir los horizontes para ganar 
comprensión; si ORTEGA habla del conocimiento obtenido por hilvanar aspectos de la realidad obtenidos gracias al desplazamiento progresivo del punto de vista, Gadamer prefiere hablar de comprensión como el fenómeno que disuelve un horizonte en otro, pues «comprender es siempre un proceso de fusión de estos presuntos 'horizontes para sí mismos'»(GADAMER, 1995, pp. 376-377); mientras que Ortega recalca que por muchas miradas que dediquemos a los escorzos de la realidad nunca la tendremos al completo, Gadamer atribuye tal dificultad a la constitutiva finitud humana; si Ortega enfatiza los alineamientos entre objeto y sujeto, Gadamer concede más importancia a la contribución activa del sujeto en la intención interpretativa.

Cuando Ortega propone el ejemplo de la sierra de Guadarrama, en donde el observador situado en El Escorial divisa el plano contrapuesto al que disfruta el de Segovia (cfr. ORTEGa, 1987b, p. 147), intenta ilustrar su teoría del punto de vista para aplicarla al tema de la verdad: "¿Tendría sentido que disputásemos los dos sobre cuál de ambas visiones es la verdadera?»(ORTEGA, 1966a, p. 23). Si el observador madrileño sólo dispone de un horizonte relativo a su posición, ¿cómo podría conocer el horizonte inverso?: o bien yendo a Segovia para contemplar las mismas montañas desde otro ángulo, o bien conversando con su correlativo observador para intercambiar sus puntos de vista. En el primer caso podría, por sí mismo, expandir su representación de la sierra, ya que contaría con dos escenas complementarias: "ganar un horizonte quiere decir siempre aprender a ver más allá de lo cercano y de lo muy cercano, no desatenderlo, sino precisamente verlo mejor integrándolo en un todo más grande»(GADAMER, 1995, pp. 375). En el segundo caso necesitaría del intercambio lingüístico de impresiones para hacerse una composición de lugar o, mejor dicho, de los dos lugares: «esta fusión de horizontes que tiene lugar en la comprensión es el rendimiento genuino del lenguaje» (GADAMER, 1995, pp. 456), o como lo expresa ORTEGA (1987b, p. 151): «la verdad integral sólo se obtiene articulando lo que el prójimo ve con lo que yo veo».

El circuito por el cual nos desenvolvemos en la vida determina nuestras experiencias. H. Minkowski acuñó el concepto de «línea de universo» para aludir al conjunto de posiciones de un punto móvil respecto a un sistema de coordenadas espacio-temporales, desde donde es posible acumular series coordinadas de perspectivas: «la "línea de universo" de cada individuo está condicionada socialmente, la posibilidad de pasar por uno o por otro punto del espacio no es aleatoria, cada individuo está atrapado por su red de relaciones sociales, hay puntos del espacio-tiempo social que nunca atravesará" (IBÁÑEZ, 1986, p. 25). Esto no significa que no seamos libres, sino que no todo puede ser recogido desde nuestras perspectivas, obligándonos a recurrir a las ya usadas por otros: "la mayor parte de los individuos quedan confinados durante toda su vida en la red de sus "lineas de universo» más probables. Su conocimiento de la realidad social se verá afectado, pues la 'linea de universo' que efectivamente recorra agota todos sus puntos de observación posibles; de los restantes sólo recibirá referencias de segunda mano o ninguna referencia» (IBÁÑEZ, 1986, pp. 25-26). En efecto, no todos vivimos idénticas experiencias; cada una es única, irrepetible e irreemplazable pero, aún así, se pueden compartir fundiendo los horizontes personales gracias al lenguaje.

Una manera provechosa de ilustrar esta teoría del punto de vista, es recurriendo a un objeto por el que podamos evolucionar en su interior, algo con un espectro amplio de propiedades organolépticas que nos proporcione una gama de sensaciones distendida en el tiempo, y así comprobaremos cómo la fusión de horizontes se produce de forma continuada. Imaginemos las posibilidades que se despliegan cuando el objeto considerado es un bosque. Un bosque no es sólo una colección de árboles, sino que constituye un entorno más extenso, variado y complejo. Nos sumergimos en él y lo observamos 
desde dentro. Seguimos paseando y miramos a nuestro alrededor: «los árboles que antes veía serán sustituidos por otros análogos. Se irá el bosque descomponiendo, desgranando en una serie de trozos sucesivamente visibles. Pero nunca lo hallaré alli donde me encuentre. El bosque huye de los ojos» (ORTEGa, 1998a, p. 101). Estamos inmersos en él y resulta que no podemos verlo, tan sólo sectores y vistas parciales, y da igual qué dirección tomemos. El árbol lejano parecerá más pequeño que el cercano, pero si nos desplazamos hacia el primero, su tamaño crecerá al tiempo que los otros irán menguando. ¿No será, como sospecha ORTEGa (1998a, p. 103), que los árboles no nos dejan ver el bosque?: «cuando se repite la frase 'los árboles no nos dejan ver el bosque', tal vez no se entiende su riguroso significado. (...) La misión de los árboles patentes es hacer latente el resto de ellos, y sólo cuando nos damos perfecta cuenta de que el paisaje visible está ocultando otros paisajes invisibles nos sentimos dentro del bosque».

El juego oscilante entre patencia y latencia nos instala en el bosque para guardar con él cierta distancia: "el bosque está siempre un poco más allá de donde nosotros estamos. De donde nosotros estamos acaba de marcharse y queda sólo su huella aún fresca» (ORTEGA, 1998a, p. 102). ¿Qué hay en el bosque además de árboles?: hojas tiernas o secas, rocas, pájaros, arbustos, movimiento de ramas, silbidos ventosos, olores húmedos y templados. Resulta que los árboles y nosotros no éramos sus únicos huéspedes. Había muchas más cosas asociadas al foco de nuestra experiencia: «toda cosa singular percibida lleva consigo su horizonte de otras percepciones posibles» (LANDGREBE, 1968, p. 64). Cada serie tramada de percepciones sobre objetos singulares (flores, insectos, piedras, nidos, setas, raíces, luces y sombras, ecos y ruidos de fondo), junto con su horizonte asociado, queda dimensionada bajo dos ejes básicos que se cruzan; el espacial: para nuestra aprehensión la cosa sólo es el trozo de mundo que nos es directamente accesible (cfr. LANDGREBE, 1968, p. 64); y el temporal: «el horizonte de una cosa (...) es también un horizonte extendido temporalmente. (...) La cosa, pues, con su concreto contenido de determinación, se remite al pasado y al futuro» (LANDGREBE, 1968, p. 65). Al hablar de percepción solemos pensar en el aquí y ahora, pero la percepción implica memoria y proyecto. Las caras posibles de un árbol, por ejemplo, nunca se darán a la vez y, sin embargo, anticipo mi percepción futura de los planos que podría ver si yo estuviera en otras posiciones. Así, en cada percepción presente hay una remisión a otras experiencias pasadas o futuras. Las cosas se dan a la percepción entre expectativa y retención. Una canción, por ejemplo, tiene un pasado y un futuro, y no sólo el punto actual de transcurso: la percepción actúa en el presente, "pero se presupone que este presente tiene tras de sí un pasado 'infinito' y ante sí un 'futuro' abierto" (Husserl, 1999, p. 168).

Pero aún hay más. Para ORTEga (1966a, p. 24), «la perspectiva visual y la intelectual se complican con la perspectiva de la valoración». Esta co-implicación tiene que ver con la elección de perspectiva según intereses y deseos. Es cierto que nuestras perspectivas valorativas, ya lo sean en cuanto al plano ético o con respecto a cualquier otro, tienen que ver con nuestros intereses, pero no por ello compartimos con GRONDIN (1999, p. 36) la idea de que «cualquier perspectiva es sospechosa de consistir en un acomodar el mundo en el sentido de una voluntad de poderío». Quizá toda perspectiva implique acomodar el mundo en un "sentido determinado», pero ésta no sólo depende de nosotros sino también del mundo, y ese «sentido determinado» no tiene por qué ser una voluntad de poder, sino que puede tratarse de una voluntad hermenéutica y, como tal, no dominada por la hybris o el dogmatismo, porque la última palabra siempre está por llegar: «la sola perspectiva falsa es esa que pretende ser la única»(ORTEGA, 1987b, p. 149). El mundo se plasma sobre un abanico de perspectivas, pero el sujeto no es un ser neutral, pasivo y conformista, sino que expresa sus preferencias en función de la captación selectiva de 
esa realidad pluridimensional, porque puede posicionarse alternativamente en diferentes puntos dependiendo de sus afectos, motivaciones y deseos. El bosque se nos ofrecía con todos sus colores, detalles e intensidades en perspectivas diversas, pero nosotros éramos los que nos deteníamos más ante una flor que ante un nido, y ahí estaba actuando el deseo: «el paisaje ordena sus tamaños y sus distancias de acuerdo con nuestra retina, y nuestro corazón reparte los acentos»(ORTEGA, 1966a, p. 24). Hicimos recaer la tilde afectiva sobre los planos de la realidad que más nos cautivaban. Esto significa que la existencia individual no se desarrolla al margen del mundo, que «mi realidad es también realidad, es parte, o, mejor aún, ingrediente constitutivo de la realidad» (MARÍAs, 1973, p. 178). Sensibilidad, percepción, deseo, sentimiento, lenguaje, imaginación, valoración y razón son ingredientes propios de la perspectiva, porque ésta no es inerte ni estática, no se limita a reflejar los entes distantes que están ahí, sino que interviene sobre la realidad que los muestra.

\section{LENGUAJE, METÁFORA y PERSPECTIVA}

El lenguaje no sólo es código, no tiene únicamente una función denominativa y comunicacional. Tampoco hay por qué reducirlo a su faceta proferencial ni restringir su alcance al mero intercambio de información, a la semiótica del significante y del significado, o a su proyección estándar sobre la tríada sintaxis-semántica-pragmática. El lenguaje no se puede objetivar porque es justamente lo que permite toda objetivación, incluida la de sus efectos. El lenguaje es el gran mediador pero no un instrumento, pues éste puede tomarse y dejarse a voluntad, mientras que el lenguaje, no. La mediación lingüística se da sobre tres planos que se disponen en intersecciones diversas y cambiantes: el del sujeto consigo mismo, con los demás, y con las cosas, siendo atravesado por el lenguaje hasta el punto de que más que hablarlo es colonizado por éste. La función metafórica es el correlato del núcleo hermenéutico de tomar algo en términos de otro algo. Esos «algos» pertenecen a la realidad y se vinculan con el sujeto gracias a las perspectivas manejadas y, además, éstas ya contienen el ingrediente desiderativo por el que el sujeto filtra y determina las acepciones: «la metaforicidad fundamental del lenguaje está en la base de la hermenéutica» (LÓPEz, 1999, p. 248). Esta metaforicidad fundamental implica que la metáfora no es posterior al lenguaje, sino cooriginaria.

Si pretendimos forjar en el epígrafe anterior un concepto lo suficientemente seguro de perspectiva, es para que aguante en éste su inserción en la tesis de que las metáforas utilizan perspectivas y, por ello, pueden ocultar o descubrir, empobrecer o enfatizar aspectos de la realidad. Pero ya la doctrina del punto de vista de Ortega, con su dimensión desiderativa y lingüística, nos proporciona un primer acceso hermenéutico a esa realidad que deseamos, percibimos y decimos. Si cada perspectiva contiene el ingrediente fundamental del deseo, pues «en toda perspectiva completa hay un plano donde hacen su vida las cosas deseadas» (ORTEGa, 1966a, p. 25), y si además, esa misma realidad es la que no sólo percibimos sino la que también valoramos ética y estéticamente mediante el lenguaje, se impondrá una conclusión: toda esta urdimbre vital nos conduce a una nueva relación con la realidad, en donde la metáfora se erige como la forma eminente de ser, interpretar y conocer.

Quizá sea difícil ahora pensar que el trasunto epistemológico se reduce al encuentro de un sujeto con un objeto ya acabados. En realidad, el sujeto está siempre en formación y resuelve su relación con el objeto en diferentes etapas hermenéuticas, pues nunca es dado en su plenitud, en todas sus posibilidades. Si el lenguaje es lo que posibilita 
toda objetivación y, además, éste es, en parte, lo que constituye al sujeto, la metáfora se presentará en su momento hermenéutico como la intermediación entre el sujeto y el mundo. La metáfora sitúa en conjunción el objeto y el sujeto; no es que aparezca luego, sino que es lo que permite que haya dos polos a vincular. Por una parte, el lenguaje de la metáfora en perspectiva hace que se muestre el mundo en toda su riqueza: «de no ser por la palabra la realidad no podría ser 'vista»' (MAILLARD, 1992, p. 52); y, por otra, esa misma palabra es la que facilita la relación mediadora como proferencia, porque «no es posible entender la realidad sin interpretarla: todo decir es interpretación» (MAILLARD, 1992, p. 47). No extrañará, pues, que el sujeto instalado perspectivamente en la realidad, invente y desarrolle un lenguaje metafórico según los puntos de vista que cose al mundo para revelar los aspectos que éste le muestra. El sujeto interpreta la realidad, es decir, «toma algo por algo» en función de las metáforas en perspectiva que aplica lingüísticamente a los «algos», extrayendo el impulso para ello del deseo. Ya no extrañará tampoco que este sujeto deseante, angular y lingüístico tome, por ejemplo, un ciprés por el espectro de una llama, haciendo de tal interpretación una metáfora bajo la perspectiva que su deseo le dicta. El único modo de tratar con la realidad es prestándonos a ese juego de vistas, razones y querencias que el lenguaje proyecta en sus metáforas según el punto de vista. ¿Cómo un sujeto sin deseos podría fijarse en algo y, además, ver allí otra cosa sin olvidar lo que era? Se nos podría decir: "pero el ciprés está ahí y sigue siendo un ciprés», pero responderíamos: "sí, pero no siempre veo un ciprés, a veces veo también el espectro de una llama; es más, cuando asimilo en mi proferencia el espectro de una llama a un ciprés, usted sabe de qué hablo». La mediación lingüística que mantiene el sujeto con la realidad se efectúa en sucesivos actos de apropiación, logrados por la perspectiva que activa cada metáfora. Por eso, fue tan importante en el punto anterior construir un concepto de perspectiva tan prolijo, ya que ésta es la brújula que orienta el sentido conector de la partícula «por» (o «como») en la fórmula hermenéutica gadameriana («tomar 'algo' por algo»).

Recapitulemos: 1) la perspectiva no es algo subjetivo porque pertenece tanto a la realidad como al sujeto; 2) no existe una perspectiva privilegiada, pues formamos una multitud variopinta de sujetos equivalentes que habitamos una realidad cambiante; 3) la perspectiva hace que la cosa no se pueda conocer por entero sino a través de tomas parciales; 4) la perspectiva no sólo es una propiedad del sentido de la vista sino que es extrapolable a cualquier ámbito de la experiencia; 5) cada perspectiva constituye un contexto, un horizonte que hemos de fusionar con otros para producir comprensión; 6) en cada panorama no aparecen al instante todos los detalles sino que lo hacen poco a poco sin llegar a agotarlo; 7) el encaje de perspectivas nos lleva en la vida sobre un circuito de vivencias posibles, ya sean de primera mano u obtenidas en el diálogo; y 8) en la perspectiva va incluido el factor valorativo y desiderativo por el que elegimos una vista en vez de otra, es decir, algo aparece porque otra cosa se oculta.

Sobre este nuevo paisaje ahora podría hacer fortuna la siguiente noción aproximativa de lenguaje: con el término "lenguaje' pretendo designar todo elemento de la experiencia humana que no es meramente contemplado por sí mismo, sino utilizado para 'significar', 'designar' o hacer las veces de algo que está más allá de él» (WhEELWRIGHT, 1979, p. 29). La descripción es interesante porque, en primer lugar, se refiere a elementos de la experiencia que han llegado a formar parte de la cadena de apropiaciones, lo cual quiere decir que cada elemento nuevo incorporado cobra su relevancia en función de los ya retenidos; también afirma que esos elementos no son tenidos en cuenta por sí mismos, sino para significar y designar, es decir, apuntan a otras cosas de la realidad, por lo que establecen un vínculo con éstas y con quien los utiliza; y, para finalizar, añade que esos 
elementos están en el lugar de cosas que no tienen por qué estar presentes. Gestos, actitudes, sueños, síntomas, relaciones genealógicas, patrones de medida o rituales religiosos, entonces, se ajustan a tal caracterización.

Imaginemos que al ver una rama de fresno la consideramos bajo la acepción de un arco, es decir, «tomamos una rama por un arco»: he ahí el deseo, el lenguaje, la interpretación, la metáfora, la perspectiva y la realidad. Un segmento de intermediación ha cruzado de un lugar a otro, hicimos pasar la rama del árbol hasta el arco en nuestras manos. Con el deseo de conseguir un arco adoptamos un punto de vista que ocultó las posibilidades de la rama como lanza, bastón, pértiga o caña de pescar, pero nos mostró la metáfora del arco flexible y resistente: «la denominación metafórica (...) no consiste en percibir el orden de una estructura, sino en "olvidar» (...) muchos atributos que el término metaforizado evoca en nosotros en su empleo normal» (Ricoeur, 1977, p. 164). La realidad parecía dormida e inexpresiva, pero al penetrar en ella mediante un deseo en perspectiva, se nos hizo patente la palabra allí (en el mundo) y aquí (en la mente). Recogimos la representación de la rama en los términos lingüísticos y conceptuales de un arco, porque así la concebimos según nuestros intereses. Y así recreamos el primer contexto sobre el segundo (N. Goodman), produciendo una interacción (M. Black) o una fusión de horizontes (Gadamer) según una perspectiva (Ortega): «gran parte del contexto no es algo previamente dado, sino que surge en el acto de la propia manera de decir. El nuevo contexto puede ser considerado como un ángulo de visión, como una perspectiva a través de la cual podemos contemplar la realidad» (Wheelwright, 1979, p. 172). Por eso, cualquier palabra, enunciado, expresión, frase, discurso u obra literaria puede convertirse en un portador metafórico, dependiendo del contexto, de la perspectiva.

Ramas como arcos, cipreses como espectros de llamas, redes informáticas como autopistas de la información, cascadas como melenas, ojos como brillos de un imán, ejemplos como gotas de sudor o contextos como perspectivas. Este «como» nivelador no es el de las teorías metafóricas de la sustitución o de la comparación, sino el mismo que actúa en la estructura hermenéutica del interpretar («tomar algo 'como' algo», «etwas als etwas»), aunque cuando interpretamos podemos estar haciendo más cosas a la vez: sustituir, comparar, asimilar, reducir, superponer, desglosar, abstraer, ocultar, destacar, cubrir, enfatizar, atribuir, diferenciar, identificar, y muchas más acciones de las que justamente sustituir no sería la más relevante, pues el efecto de una sustitución no siempre genera una metáfora o una interpretación. Lo que ocurre en la metáfora es que dos acepciones se enlazan en una interacción tensiva. La relación entre metáfora y perspectiva se manifiesta con toda claridad: «las metáforas, más que descubrir propiedades de lo real previamente existentes, nos sirven para ver el mundo con arreglo a diferentes perspectivas» (Bustos, 2000, p. 105). Lo que hace la metáfora es vincular, integrar y relacionar, es decir, atar con el lazo del punto de vista.

Metaforizar es un acto creativo, y el propio hecho de nombrar una cosa, una relación o un fenómeno, es elegir un punto de vista para que la asignación soporte el nuevo peso semántico: «nombrar no consiste en dar nombre a algo ya conocido anteriormente, sino en abrir una perspectiva antes no habida por el simple hecho de no haber sido vista» (Maillard, 1992, p. 51). Percibir no es algo pasivo, sino que imprime su sello simbólico a los objetos que descubre e interpreta; se trata de una capacidad sensomotriz adiestrada hermenéuticamente por el lenguaje, o como dice GeHLEN (1980, pp. 252-253): «cuando nuestra acción toma objetos (de por sí muy distintos) bajo un punto de vista común, quiere decirse que existe una estructura simbólica de la percepción. (...) Este proceso consiste (...) en que A sea tomado como $B$ ». Y la elección de la perspectiva no sólo tiene que ver con criterios estrictamente lógicos, sino también afectivos. La eficacia de la metáfora 
nos muestra que el enlace que promueve es recíproco, y por ello capaz de ensanchar conceptos, de fundirlos sin confundirlos, lo que significa que la brecha hermenéutica que abre, apunta más hacia un tipo de conocimiento expansivo y relacional que a otro más acumulativo y enciclopédico. La metáfora es un proceso de formación de conceptos: «cuando una palabra se transfiere de una cosa a otra para que ésta resulte inteligible, el concepto se expande (...). La metáfora es la base lingüística que encarna la naturaleza bilateral y recíproca de la aplicación: mientras que la inducción y la deducción proceden de forma unidireccional de lo particular a lo universal y viceversa, la metáfora origina un movimiento reversible y circular» (LóPEz, 1999, p. 248).

La metáfora trabaja a partir de un punto de vista fijado por el deseo, y así asume una relación hermenéutica entre dos elementos que se suponían conceptualmente distantes y heterogéneos, pero gracias a la aplicación interpretativa logra aportar un excedente de sentido. El proceso podría explicarse así: «En la dicción algo que en la vivencia inmediata se da de un modo aislado y en toda su peculiaridad (A) [ "el espectro de una llama», es decir, la experiencia sugerida con respecto a la realidad considerada] queda vinculado a una palabra que es portadora de un determinado significado más o menos general (B) ["ciprés», es decir, el nombre de ese árbol], con lo que es sacado de su aislamiento y su particularidad, puesto en correlación con una serie de cosas y diferenciado de otras muchas. Ahora bien, puesto que (B) [el «ciprés»] no puede coincidir nunca totalmente con (A) [el "espectro de una llama»], lo que ocurre es que se está tomando a (B) [un "ciprés»] por (A) [el «espectro de una llama»], se está viendo a (B) como (A)» (GARAGALZA, 2002, pp. 2223). La más elemental designación conlleva un proceso metafórico y de simbolización, ya que el uso de dos elementos, A y B, provoca con su superposición el desprendimiento de rasgos simbólicos intercambiables.

Podemos señalar parecidos entre dos elementos que al traspasar contextos funcionan semánticamente en cada uno de ellos de distinto modo, equiparar aspectos bajo una cierta perspectiva, concebir semejanzas en base a detalles no esenciales; pero siempre es el sujeto quien propone la «semejanza en cuanto a...»: "¿qué es percibir lo semejante sino instaurar la semejanza misma acercando términos que, "alejados» al principio, aparecen "próximos» de pronto?»(RIcoeUR, 2000, p. 32). La clave para la interpretación de la metáfora no consiste sólo en el hallazgo, a veces ineficaz, de analogías, equivalencias o similitudes, sino en redescribir la realidad a base de sucesivas simbolizaciones para dotarla de peso ontológico. Por usar la imagen de las fichas de dominó: podemos distinguir entre el ensamblaje lineal organizado según el valor de cada ficha, y otro tipo de construcción determinado por la disposición de esas mismas fichas como si fueran módulos de edificación en una maqueta.

La metáfora viva no se limita a pasar al lenguaje «algo visto como otro algo», sino que hace de la perspectiva utilizada el puente por el que, por ejemplo, una rama se convierte en un arco sin que la rama se esfume: «me he arriesgado a hablar (...) de referencia metafórica, para expresar este poder que tiene el enunciado metafórico de re-describir una realidad inaccesible a la descripción directa. Incluso he sugerido hacer del "ver-como» (...) el revelador de un "ser-como», en el plano ontológico más radical» (RicoeuR, 2000, p. 33). En la metáfora no hay reemplazo de conceptos o imágenes, sino compenetración y condensación. Lo que sucede es que hay un solo lugar en la cadena sintagmática para la superposición de dos ideas o interpretaciones. Tal simultaneidad hace que ninguna imagen se pierda, y que la transferencia a la que alude la definición clásica sea siempre mutua entre los términos implicados. La metáfora pertenece al locus común que es ocupado por dos modos de ver, de ser y de decir algo en sincronicidad. Para que haya metáfora es preciso que haya conciencia del doble significado de la expresión que la 
presenta. Por eso, el error, el olvido o la simplicidad de las teorías tradicionales de la metáfora estriba «en tener en cuenta solamente el elemento focal y no los dos elementos en conexión» (MaIllard, 1992, p. 104).

\section{El REVERso de LA metáFora}

Las metáforas que se pueden componer son ilimitadas, lo mismo que las perspectivas usadas para ello. A pesar del esfuerzo por clasificar las metáforas en unos cuantos tipos básicos, los resultados no han conseguido reflejar un número reducido. ORTEGA (1966b, pp. 213 y 214) propuso dos grandes metáforas; la del realismo, que se refiere al sello impreso en la superficie de cera: «cuando mente y objeto se tropiezan deja éste en aquélla su traza impresa»; y la del idealismo, que sustituye la cera y el cuño por el contenido y el continente: "las cosas no vienen de fuera a la conciencia, sino que son contenidos de ella, son ideas». Pero estas dos metáforas ya parten de la perspectiva de la conciencia y su otro, donde éste es capturado como marca o como contenido, es decir, expresan la retención del objeto por el sujeto. MaILlaRd (1992, p. 119) añade una tercera: «el hombre es luz que alumbra el universo». Pero igualmente aquí vemos cómo el ángulo de visión es el mismo, el de un sujeto que aprehende o atrapa, de alguna manera, los objetos que pueblan el mundo. LAKOFF y Johnson (ver 1998, pp. 39-72) también tipificaron algunas metáforas: las estructurales, en donde un concepto se articula en términos de otro; las orientacionales, que organizan un sistema de conceptos en relación a otro considerando las referencias espaciotemporales; y también hablan de metáforas ontológicas, de recipiente, de sustancia, de actividad o de estado.

Pero cada metáfora, sea del tipo que sea, destaca un punto de vista al tiempo que desactiva otros. Por ejemplo, al decir que cada ejemplo propuesto es una gota de sudor, recalcamos el esfuerzo que supone improvisar una nueva imagen para ilustrar un asunto determinado, pero al elegir tal punto de vista obviamos otro, que podría ser que cada ejemplo es una puerta más que abrimos. Si tomamos una rama como un arco ya no la veremos como un arpón, si consideramos unos ojos como brillos de un imán perderemos la acepción de ventanas del alma, si entendemos las redes informáticas como autopistas de la información se nos escapará pensarlas como tejido neuronal, o si decimos de una conversación que es una guerra de dardos ya no la veremos como un intercambio cooperativo. Esto quiere decir que el poder semántico y conceptual de la metáfora viene dado por el tipo de asociación que activa en detrimento de otros: «la metáfora permite una nueva visión, una nueva organización del universo, un nuevo orden, pero lo realmente nuevo son las asociaciones que permiten ese nuevo orden. Inventar una metáfora es crear asociaciones» (MAILlARD, 1992, p. 161).

En este sentido, nos gustaría mencionar la metáfora del canal, propuesta por M. REDDY, que concibe el lenguaje como algo estrictamente comunicacional, olvidando la relevancia de las circunstancias: "la metáfora del 'canal', que se puede formular como 'las expresiones lingüisticas son recipientes para los significados', supone que las palabras y las sentencias tienen significados en sí mismas, independientemente de cualquier contexto o hablante» (LAKoff y JoHnson, 1998, p. 47). Es decir, los significados se introducen en expresiones lingüísticas como la carga de un contenedor, con lo que el lenguaje se reduce a enviar de un sujeto a otro estos contenedores de significados: hacer llegar una idea, colocar ideas en palabras, llevar una idea a buen puerto, palabras vacías, poner más pensamientos en menos palabras, llenar de ideas el discurso, o ideas enterradas en largos párrafos. Cuando esta perspectiva metafórica llega a cuajar, no extrañará que se 
acepte que el significado está en las palabras, y lo único que hay que hacer es extraerlo. Al enfatizar un punto de vista los otros se dejan de lado. Nosotros mismos hemos sufrido esta metáfora del canal, sobre todo al defender la idea de que el lenguaje no sólo transporta información, que la comunicación es algo importante pero no hay que reducir el lenguaje al clásico esquema de C. Shannon, que cuando hablamos en silencio con nosotros mismos no conducimos ninguna idea de un emisor a un receptor a través de ningún canal, que el lenguaje actúa cuando reconocemos un perro en una nube.

Sin embargo, la clave hermenéutica de la metáfora consiste en que nos obliga a salir del canal, a desbordarlo y a mezclar las aguas de distintas acequias. La metáfora del canal acentúa una perspectiva por haber ocultado otras: las palabras son los ladrillos de las ideas, palabras secas, el lenguaje es un instrumento, el lenguaje es el espejo de la naturaleza, las palabras son los fotogramas del cine del discurso, el verbum interius es la tramoya del lenguaje, el lenguaje nos permite ver reflexivamente, la expresión metafórica es un interruptor que abre una posibilidad semántica al tiempo que cierra otra. Estas otras metáforas, al enfatizar nuevas perspectivas por las que entender lo que es el lenguaje, nos impiden concebirlo en función de un canal. La metáfora se muestra así no sólo como el correlato interpretativo del «tomar algo por algo», sino como un poderoso artificio de encubrimiento y ocultación.

La metaforicidad fundamental del lenguaje hace que el hecho de «estar en él» nos introduzca en su juego de luces y sombras. Sucede lo mismo que al entrar en una gruta con una antorcha: sólo ganamos una visión parcial gracias a la luz (lenguaje), y si queremos ver otras zonas tendremos de acercarnos a éstas (deseo), provocando que el lugar de donde venimos regrese a las tinieblas. Podemos ir y venir con la tea cuanto queramos, pero el resto oscuro de la cueva seguirá esperando a ser revelado. Igual sucede con esa realidad que queremos decir y expresar, aunque a veces se nos escape, pues la estructura lingüística encargada de decir borra, al menos en parte, el significado (cfr. Gadamer y VietTa, 2004, p. 84); idea que comparte Maillard, (1992, p. 117): «cualquier lenguaje, por ser mediador, oculta parcialmente lo que pretende desvelar». Como el lenguaje es el mediador entre el sujeto consigo mismo, con la realidad, y con los demás, lo otro, la zona oscura, vivirá en cada uno de nosotros y en la realidad, pero también en el sistema del lenguaje, ese que no puede decirlo todo y que, además, niega y reprime las perspectivas más "peligrosas». Este es el reverso de la metáfora, justamente lo que su punto de vista sustituye, desplaza y reprime, lo que condena a la penumbra y al olvido, como el prestidigitador que llama la atención sobre una mano para que la otra actúe sin ser vista: subraya una perspectiva para que perdamos otras.

\section{De La PERSPECTIVA PSICOANALÍtica AL SÍMBOLO}

¿Qué sucede cuando inconscientemente actuamos en sueños, alucinaciones o fantasías como el prestidigitador? ¿No eludimos, acaso, un punto de vista que nos pudiera conectar con algo desagradable y, por eso, elegimos otro?: «en el desplazamiento o la sustitución, lo consciente es también deformado y la angustia parcialmente controlada, representándose erróneamente el objeto del impulso peligroso como algo distinto al objeto real, como cuando Juanito le tiene miedo a los caballos más que a su padre» (MADIson, 2001, p. 45). Se trata de una metáfora que hace más soportable la angustia: el padre, verdadero objeto de su angustia, es eclipsado por los caballos que aparecen en la proyección alternativa para paliar el sufrimiento: «el padre tenía que ser el caballo al cual, y por excelentes razones internas, tenía miedo»(Freud, 1982, p. 157). Tal metáfora inconsciente 
sirve como defensa para proteger al yo de las exigencias pulsionales que le causarían estragos. Como vemos, la metáfora no sólo interpreta, sino que también tiene su reverso, pues si interpreta al tomar algo como algo, también encripta, esconde, oculta, censura y reprime otros contenidos, y por eso constituye el modelo del mecanismo de la represión. Para Freud (cfr. 1989, p. 142), tal mecanismo no trabaja borrando una representación intolerable, sino impidiendo que se haga consciente o deformándola para que se convierta en algo aceptable para el yo. La represión actúa como una defensa, esto es, "como el intento de controlar la angustia mediante una deformación de lo consciente» (Madison, 2001, p. 46). El deseo se oculta en el inconsciente y desde ahí aflora por los resquicios que permite la defensa represiva para situarse en las metáforas. El formato lingüístico por el que los deseos emergen, presenta la misma apariencia estructural que ese ser que, al ser comprendido, puede ser dicho en su modalidad circunstancial y perspectiva, muchas veces sombreado por el discurso metafórico que nos sorprende, por dejar en suspenso el acceso semántico más esperado. ¿Qué habremos deseado, sin saberlo, cuando creímos ver a una persona entre la multitud, y después supimos que era imposible que estuviera allí? ¿Qué deseo habrá reprimido aquel adulto que, curándose en salud, avisa a ese niño molesto que es el centro de atención para que retire su dedo del quicio de la puerta?

Antes de temer a los caballos eran los animales favoritos de Juanito. ¿Qué relación existía entre los caballos y el padre? ¿Qué perspectiva dispuso en conjunción los caballos con su padre, y por qué la hizo invisible? Si le gustaban tanto los caballos, ¿por qué los seleccionó inconscientemente en la metáfora represora para asociarlos al padre, que era a quien realmente tenía miedo?: "nuestra sospecha de que el padre hubiera sido el primero en servirle de caballo nos fue confirmada por él mismo (...). Una vez iniciada la represión, Juanito tenía que asustarse de los caballos, que antes le habian procurado tanto placer» (Freud, 1982, p. 160). Como se ve, la fobia suele aparecer más cerca de la filia que de la indiferencia, y quizá el inconsciente no sea un lugar tan seguro como parece. Al final, la energía usada en la represión no sale a cuenta, y los objetos reprimidos tienden a emerger del modo más insospechado: ahí están nuestros síntomas, aunque a veces los confundamos con los rasgos más propios de nuestro carácter. Si deseamos algo, ¿por qué no reconocerlo? ¿Por qué la realización de nuestros deseos, aunque sea en forma de suceso alucinatorio onírico, a veces nos depara más rechazo que placer, como así lo reconoce FREUD (1998, p. 227) refiriéndose a la satisfacción del deseo en los sueños?: «la realización de los mismos no puede procurar placer alguno, sino todo lo contrario». La actitud que mostramos ante ciertos deseos puede tomar un cariz ambivalente; una parte de nosotros pretende que éstos se satisfagan, pero la otra intenta censurar esta posibilidad porque, tal vez, supondría enfrentarse a efectos devastadores: «la pesadilla es muchas veces una realización no encubierta de un deseo, pero de un deseo que lejos de ser bien acogido por nosotros es rechazado y reprimido» (FREUD, 1998, p. 228).

El caso Juanito sólo nos interesa aquí en la medida en que genera un tipo de instancia simbólica de carácter inconsciente, por la que una metáfora apunta a un síntoma (miedo a los caballos), ocultando la perspectiva en donde éste se originó (miedo al padre): "la función de la metáfora consiste precisamente en reemplazar el simbolismo, cuyas raíces están siempre en las pulsiones prohibidas, por una inofensiva interpretación de lo abstracto en un revestimiento imaginativo" (RICoevR, 1978, p. 442). Nos encontramos con la doble función de los elementos mediadores: a la vez que unen, separan; a la vez que vinculan, distinguen. Son como los puentes, que aproximan los márgenes al tiempo que remarcan la alteridad recíproca de cada orilla; como las fronteras, que dividen y ensamblan. Es la ley del símbolo, que se especializa en tender accesos posibles e 
imposibles. Posibles, porque acreditan el descubrimiento de asociaciones hermenéuticas, al liberar en el horizonte de comprensión una trama coherente de relaciones por la que transitar para apropiamos parcialmente del mundo; e imposibles, porque silencian otras proyecciones más acordes con los deseos ignotos.

Si un símbolo pudiera decirlo todo dejaría de serlo, lo mismo que la metáfora y la interpretación. Sólo es posible simbolizar cuando algo falta: «los verdaderos símbolos se sitúan en la encrucijada de dos funciones (...). A la vez que encubren, descubren; a la vez que ocultan los objetivos de nuestras pulsiones, revelan el proceso de la conciencia de sí: encubrir y descubrir; ocultar y mostrar; estas dos funciones no son totalmente exteriores la una de la otra, sino que expresan dos caras de la única función simbólica» (RICOEUR, 1978, p. 434). En la génesis de la conciencia tuvo que aparecer una alteridad que evolucionó hacia lo reflexivo y lo recíproco. La conciencia de sí fue ganada gracias a los efectos que «el otro» desencadenó, y con la madurez de la autoconciencia éstos fueron devueltos en la interacción colectiva del diálogo. La huella material y significativa de estas ligazones es el símbolo. Un símbolo era una especie de salvoconducto de identificación, recordatorio de alianza usado para salvar una separación. Consistía en un objeto que aludía al vínculo contraído por las partes en un determinado tiempo y lugar mediante la posible unión de las dos mitades del objeto dividido. Se trata de un nexo generado a partir de una ruptura, pero fijado en la contingencia de que este simple puzzle de dos piezas pueda ser resuelto. El mejor complemento de una media naranja es la otra media, por eso se trata de una resolución complementaria. "Una fracción de la que existe un complemento': perifrasis de 'symbolon' ('symballein', 'acercar', 'reunir'). El 'symbolon' es una señal de reconocimiento, un objeto de pequeño tamaño (tablilla, ficha) de la que dos personas guardan cada uno la mitad» (DROz, 1993, p. 31). Hay que construir los símbolos con el objeto, la fractura y la memoria. Pero quizá, más que de un objeto, se trate de la operación significativa que hace referencia a un reencuentro esperanzador.

Estas consideraciones sobre la arqueología del símbolo destacan la relación que asegura el lazo entre las personas involucradas en el pacto. Pero también el acontecimiento simbólico se juega en la reflexividad del sujeto. Antes y después de las trabazones entre los individuos, el sujeto puede ser concebido como un ser escindido, igual que el símbolo; por una parte, el registro revelador de la conciencia de sí y, por otra, los oscuros objetivos de las pulsiones: ambas mitades se engarzan en el sujeto como las dos caras de una moneda (Ricoeur). En este punto también incide E. Trías al concebir el sujeto como un ser dividido: un ser ni totalmente divino ni únicamente animal, tan sólo habitante del límite que a veces sale al encuentro de la otra parte, a la que asiste para provocar la chispa que ilumina por un instante, su actividad deseante, hermenéutica y ética, y que puede desembocar en una conjunción feliz de diversos niveles de comprensión. ¿Qué es, pues, el símbolo? ¿Cada parte, la conjunción de ambas, la línea fronteriza de unión o la actividad que operó en su formación?

Cada símbolo tiene su otro, su falta, su complemento, porque está situado justo en el límite, entre lo consciente y lo inconsciente, lo racional y lo irracional, lo patente y lo latente, lo pensado y lo no pensado, lo sensible y lo no sensible, lo inmanente y lo trascendente, el cielo y la tierra: el símbolo es el nexo situado «entre». Se trata, como afirma Jung, de una máquina de transformación de la energía psíquica, y como tal, capaz de reparar lo desunido y de conciliar lo discordante. Los grandes mediadores no tendrían razón de ser en un mundo absolutamente esclarecido y pleno de sentido, donde ya no hubiera nada que re-mediar o inter-mediar porque todo ya es in-mediato. Pero éste no es el caso, pues el mundo fragmentario que nos procura la perspectiva, el lenguaje, la hermenéutica y el símbolo, es experimentado entre el fogonazo efímero de la comprensión y la espesa niebla tras la que se oculta. 


\section{Bibliografía citada}

Bustos, E. (2000): La metáfora. Ensayos transdisciplinares. F.C.E. y U.N.E.D. Madrid.

Chamizo, P. J. (1990): Ortega y la cultura española. Cincel. Madrid.

Deleuze, G. (2011): Lógica del sentido. (Tr: M. Morey y V. Molina). Paidós. Barcelona.

Droz, G. (1993): Los mitos platónicos. (Tr.: D. Chiner). Labor. Barcelona.

Freud, S. (1982): «Análisis de la fobia de un niño de cinco años», en Sexualidad infantil y neurosis. (Tr.: L. López-Ballesteros). Alianza Editorial. Madrid.

- (1989): «La represión», en Obras completas (XIV). (Tr.: J. L. Etcheverry). Amorrortu. Buenos Aires.

- (1998): «Los sueños», en Introducción al psicoanálisis. (Tr.: L. López-Ballesteros). Altaya. Madrid.

Gadamer, H.-G. (1995): Verdad y método I. (Tr.: A. Agud y R. Agapito). Sígueme. Salamanca.

- (1998): El giro hermenéutico. (Tr.: A. Parada). Cátedra. Madrid.

- (2000): "La diversidad de Europa. Herencia y futuro», en La herencia de Europa. Ensayos. (Tr.: P. Giralt). Península. Barcelona.

- y Vietta, S. (2004): Hermenéutica de la Modernidad. Hans-Georg Gadamer. Conversaciones con Silvio Vietta. (Tr.: L. Elizaincín-Arrarás). Trotta. Madrid.

Garagalza, L. (2002): Introducción a la hermenéutica contemporánea. Cultura, simbolismo y sociedad. Anthropos. Barcelona.

Gehlen, A. (1980): El hombre. Su naturaleza y su lugar en el mundo. (Tr.: F.-C. Vevia). Sígueme. Salamanca.

Grondin, J. (1999): Introducción a la hermenéutica filosófica. (Tr.: A. Ackermann). Herder. Barcelona.

Husserl, E. (1999): La crisis de las ciencias europeas y la fenomenología transcendental. (Tr.: J. Muñoz y S. Mas). Altaya. Barcelona.

Ibáñez, J. (1986): Más allá de la sociología. Siglo XXI. Madrid.

Lakoff, G. y Johnson, M. (1998): Metáforas de la vida cotidiana. (Tr.: J. A. Millán y S. Narotzky). Cátedra. Madrid.

LANDGREBE, L. (1968): El camino de la fenomenología. El problema de una experiencia originaria. (Tr.: M.A. Presas). Editorial Sudamericana. Buenos Aires.

López SÁenz, Ma . C. (1999): «La universalidad del lenguaje en la filosofía hermenéutica de H. G. Gadamer», en Racionero, Q. y Royo, S. (Eds.), Revista Éndoxa. La filosofía en el fin del siglo. Materiales para un análisis del pensamiento del siglo XX. (Series Filosóficas $N^{\circ} 12$, vol. I). U.N.E.D. Madrid.

Madison, P. (2001): La represión en Freud. Su lenguaje teórico y observacional. (Tr.: E. Rodríguez). Ediciones del Laberinto. Madrid.

MAILlARD, CH. (1992): La creación por la metáfora. Anthropos. Barcelona.

Marías, J. (1971): Acerca de Ortega. Revista de Occidente. Madrid.

- (1973): Ortega. Circunstancia y vocación. (Vol. 2). Revista de Occidente. Madrid.

Nietzsche, F. (1981): La voluntad de poderío. (Tr.: A. Froufe). Edaf. Madrid.

- (1998): Sobre verdad y mentira en sentido extramoral. (Tr.: L. Valdés). Tecnos. Madrid.

- (2001): El gay saber o Gaya ciencia. (Tr.: L. Jiménez). Espasa-Calpe. Madrid.

Ortega y Gasset, J. (1966a): "Verdad y perspectiva», en El Espectador (I). Espasa-Calpe. Madrid.

- (1966b): «Las dos grandes metáforas», en El Espectador (III-IV). Espasa-Calpe. Madrid.

- (1983): «Adán y el Paraíso», en Obras completas (I). Alianza Editorial y Revista de Occidente. Madrid.

- (1987a): «Apéndices: II. El sentido histórico de la teoría de Einstein», en El tema de nuestro tiempo. Prólogo para alemanes. Apéndices y Anejos. Revista de Occidente y Alianza Editorial. Madrid.

- (1987b): «La doctrina del punto de vista», en El tema de nuestro tiempo. Prólogo para alemanes. Apéndices y Anejos.

- (1998a): Meditaciones del Quijote. Cátedra. Madrid.

- (1998b): Origen y epílogo de la filosofía. F.C.E. México.

Ricoeur, P. (1977): La metáfora viva. (Tr.: G. Baravalle). Megápolis. Buenos Aires. 
- (1978): Freud: una interpretación de la cultura. (Tr.: A. Suárez, M. Oliveira y E. Inciarte). Siglo XXI. México.

- (1999): «¿Qué es un texto?», en Historia y narratividad. (Tr.: G. Aranzueque). Paidós. Barcelona.

- (2000): Tiempo y narración. I: Configuración del tiempo en el relato histórico. (Tr.: A. Neira). Siglo XXI. México.

SAntiago Guervós, L. E. DE (1997): Gadamer (1900-). Ediciones del Orto. Madrid.

VAIHINGER, H. (1998): La voluntad de ilusión en Nietzsche. (Tr.: T. Orduña). Tecnos. Madrid.

Wheelwright, P. (1979): Metáfora y realidad. (Tr.: C. A. Gómez). Espasa-Calpe. Madrid.

Universidad Nacional de Educación a Distancia (UNED

José L. SerRano Ribeiro

España

joxelserrano@hotmail.com

[Artículo aprobado para publicación en noviembre de 2014] 